\title{
Soil Moisture Prediction using Fuzzy Time Series and Moisture sensor Technology on Shallot Farming
}

\author{
Dedy Rahman Prehanto ${ }^{1, *}$, Aries Dwi Indriyanti ${ }^{1}$, Chamdan Mashuri ${ }^{2}$ and Ginanjar Setyo Permadi ${ }^{3}$ \\ ${ }^{1}$ Informatics Engineering Department, of Engineering Faculty, Surabaya State University, Surabaya- Indonesia \\ ${ }^{2}$ Information System Department of Information Technology Faculty, Hasyim Asy'ari University, Jombang - Indonesia \\ ${ }^{3}$ Informatics Management Department of Information Technology Faculty, Hasyim Asy'ari University, Jombang - Indonesia
}

\begin{abstract}
This research conducted by predicting soil moisture using Fuzzy Time Series (FTS) and soil moisture sensor technology on shallot farming. Well-controlled soil moisture affects the shallots and crops growth. It discusses soil moisture prediction and monitoring systems developed through Android-based mobile programming languages. Input data consists of sensor results obtained from automatic, online, and real-time acquisition using soil moisture sensor technology, then, sent to the server and stored in an online database. Furthermore, data acquisition is predicted using the FTS algorithm that applies a discourse universe to define and determine fuzzy sets. Fuzzy set results are continued to the process of sharing the discourse universe so that it becomes the final step. Prediction results are displayed on the information system dashboard developed. Using 24 data from soil moisture data, the predicted score is 760 at the beginning of 6:00. The results of the prediction are done by validating error deviations using the Mean Square Error of $1.5 \%$. This proves that FTS is good enough in predicting soil moisture and safety to control soil moisture in shallots. For deeper analysis, researchers used various request data and $U$ discourse universe at FTS to obtain various results based on the test data used.
\end{abstract}

Keywords: Soil moisture; prediction; Fuzzy Time Series; moisture sensor technology; shallot farming.

\section{Introduction}

Sensors and fuzzy, sensor technology and methods/algorithms complement and assist in the research process. The method/algorithm is used as a rule or method to process data/numerical values to be converted into data that can indicate information. In this study, the session used a soil moisture sensor and applied fuzzy time series (FTS) methods/algorithms. FTS is used to process numerical values/soil moisture data as a result of soil humidity sensors that have recorded/retrieved data at the specified time.

Soil moisture is a variable from hydrology that connects between water, energy, and carbon cycles. Soil moisture is very important as a support for weather forecasting, flood forecasting, drought monitoring and climate modeling. Soil moisture can also be used as a variable for active microwave measurements and lowfrequency passive land ends sensitive to surface soil moisture and can penetrate clouds and low to moderate vegetation cover [1]. The amount of moisture in the soil is an important variable to understand the coupling of the continental surface and the atmosphere. Soil moisture initialization is also crucial in seasonal forecasting studies, since anomalies may persist at monthly to seasonal time scales [2]. Soil moisture is of fundamental importance to many hydrological, biological and biogeochemical processes, plays an important role in the development and evolution of convective weather and precipitation' and impacts precision agriculture, water resource management, and flood run off prediction [3].

Soil moisture is an element that is very influential on plant growth. The amount of absorption of solar radiation by the soil surface is a factor that greatly affects the soil temperature. The temperature of the soil during day and night is very different, during the day when the surface of the ground is heated by the sun, the air close to the ground reaches a high temperature, while at night the soil temperature decreases, soil temperature affects water absorption. The lower the temperature, the less water is absorbed by the roots, which is why a sudden drop in soil temperature can cause plants to wilt. Fluctuations in soil temperature depend on the depth of the soil [4].

Soil moisture is the amount of water stored between the porous soils. Very dynamic soil moisture is caused by evaporation through the soil surface, transpiration, and percolation. Soil moisture has an important role for farmers to find out information such as potential surface runoff and flood control, failure of soil erosion and slope, management of water resources, geotechnics, and water quality. The factors that determine soil moisture are rainfall, soil type, and the rate of evapotranspiration, soil moisture will determine the availability of water in the soil for plant growth [5].

* Corresponding author: dedyrpr@yahoo.com 
The agricultural sector has enormous potential as a state income. The agricultural sector is one of the most important sectors that enhance economic growth in the community. One of the most important factors in agriculture is the quality of agricultural land. The better the agricultural land, the agricultural products will also increase. The most important factor that affects the quality of agricultural land is soil moisture, air moisture, and air temperature are environmental conditions that can have a large effect on plant growth. If soil moisture is too high, an increase in zoospore activity caused by Phytium sp can interfere with plant health. These problems can be solved by the existence of a monitoring system for predicting soil moisture that can make it easier to measure and monitor soil and plant conditions [6].

Prediction in control and fluctuating data management is an interesting challenge for research because most work on time series data as has been done to deal with prediction problems such as predictions in information system management, health care, economic predictions, sales predictions, budget analysis, stock market fluctuations, business analysis, etc. A consistent design and prediction model is needed to achieve forecast accuracy. Due to uncertainty and some unknown parameters on soil moisture data, fuzzy time series models are the first choice for prediction purposes [7].

Prediction or forecasting has an important role in various fields such as economics, health, engineering and environment as well as agriculture. Prediction or forecasting, which is applied in an institution will be able to make a decision or policy related to what will happen next based on the data that existed before. Fuzzy time series (FTS) methods have advantages that lie in the use of historical data compared to other conventional time series methods. In the fuzzy time series (FTS) method, fuzzy sets are used as a number class with vague boundaries, or can be said, which is used in predictions with fuzzy systems are linguistic values, not real values [8]

Fuzzy time series (FTS) is able to make model prediction problems that are linguistic value with longstanding information. FTS is also able to use more predictive observations that have been applied to deal with nonlinear problems. Based on the fuzzy set theory model FTS originated by Song and Chissom in 1993, FTS was used to predict enrollment from the University of Alabama. Chen presents a new model using simple fuzzy relations and simple arithmetic calculations [9, $10]$.

Time series is a structured set of time which is composed of individual quantitative characteristics or collective phenomena taken from successive time periods. To understand the characteristics of time series, many researchers have adopted and analyzed and developed time series methods, with the ultimate goal of finding patterns or formulas that can be used to predict the future. To process time series data, many soft computing methods, such as fuzzy systems, neural networks, genetic algorithms, and hybrid methods. Especially, fuzzy and fuzzy hybrid systems approaches have been developed and applied in many areas and fields of research. Chen and Hsu have introduced a new method for estimating honorarium at the University of Alabama while Jilani, Burney, and Ardil use fuzzy time series metric approaches for prediction and develop time series methods for predictions using fuzzy inference systems, based on original works proposed by Wang and Mendel so this method is known as the fuzzy time series [8].

Soil Moisture Probe is a device made of metal material with certain materials. Moisture Probe made of metal is used as a sensor for measuring water content in the soil. The moisture probe acts like a capacitor with the ground as its dielectric. In addition, the moisture probe as a capacitance probe measuring soil moisture is a moisture probe inserted in the soil which will be measured for moisture and connected to a signal generator. If the water content (moisture) of the soil changes, the probe will produce a change in the value of the capacitance, because of the permittivity of the dielectric changes. The nature of water that has a dielectric at low-frequency measurements is very good for measuring soil moisture [1]. Changing the value of the capacitance (impedance) will change the magnitude of the frequency of the output waveform of the dielectric signal generator. Thus, the frequency of the wave output of the signal generator will change according to the soil moisture. This change in frequency will then be processed to determine the percentage of moisture in the soil [11].

Soil Moisture Probe is a device made from metal material with certain materials. Moisture Probes made of this metal are used as a sensor for measuring water content in the soil. Moisture probes act like a capacitor with soil as the dielectric. Other than that the working principle of using this sensor for measurement of soil moisture is the moisture probe inserted in the soil to be measured moisture and connected to the generator signal. If the water content (moisture) of the soil changes, the probe will produce a change in value capacitance, because of the dielectric permittivity changes. The nature of water that has a dielectric in measurement low frequency is very good for measuring soil moisture [12].

The soil moisture sensor is a sensor that is can detect soil moisture in the surrounding area. This sensor consists of two probes to pass electricity in the ground as shown in figure 2.2. Then read the resistance to get the value of the moisture level. This sensor consists of two probes to pass flow through the ground, then read resistance to getting level values moisture. More water makes land is easier to conduct electricity (small resistance), while the soil is dryness is very difficult to conduct electricity [12].

\section{Methods}

\subsection{Data Acquisition}

This data acquisition system in moisture prediction applications implements sensor technology, which is a sensor that detects groundwater in the ground and is 
processed into time series data stored on the local database on the microprocessor by using internet network historical soil moisture data sent to the web server and stored online the database is then predicted which can be seen in Fig 1.

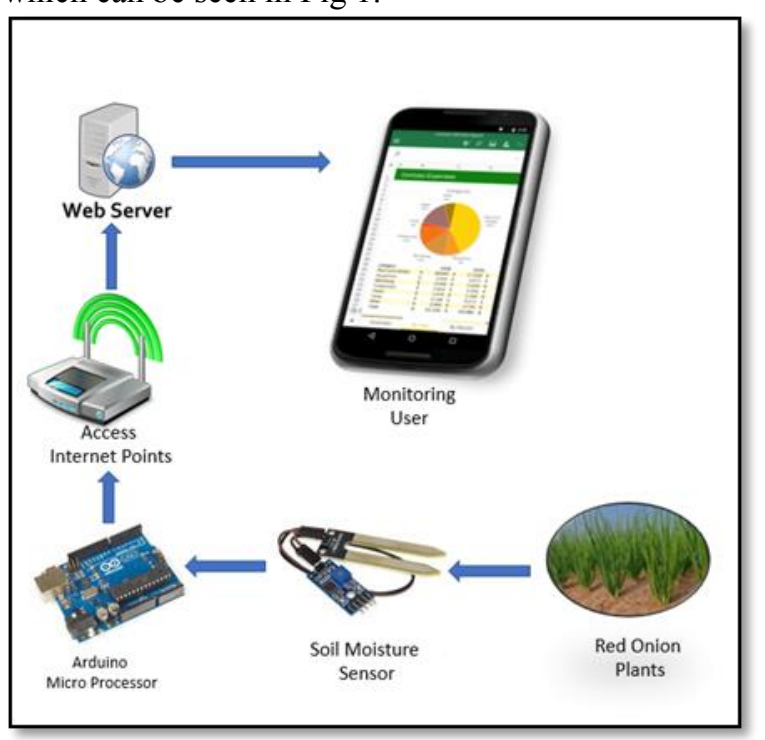

Fig. 1. Flow data acquisition

\subsection{Modelling by using fuzzy time series}

Predicting by using a fuzzy time series model is a method of data prediction using principles of fuzzy whose base is catching the formula of longtime data then used to project the future data. Modeling of prediction by using fuzzy time series has some steps as follows:

1. Defining universe of discourse $U$ until fuzzy set can be determined as $\mathrm{U}=[\mathrm{x}, \mathrm{y}]$.

2. Determining a minimal and maximal score of actual history data $(X \min =x, X \max =y)$.

3. Dividing universe of discourse $U$ with some series of data $\mathrm{u} 1, \mathrm{u} 2, \ldots$ un and determining the linguistic score.

4. Doing fuzzification and fuzzy set from data of actual histories.

5. Calculating score of fuzzy data of actual history by using the following pattern :

$$
\mu N B[x]=\frac{b-x}{b-a} 203659 \leq x \leq 471585
$$

6. Choosing the basis of model $\mathrm{W}$ which is very appropriate and calculating fuzzy using the following pattern:

$$
r(M B F)^{w+1}=\frac{M B F 1+M B F 2+\cdots+M B F w}{w}
$$

7. Doing defuzzification of calculation result from the above step then, calculating prediction result by using the following pattern :

$$
y=\frac{(A 1 * c 1+A 2 * c 2)}{A 1+A 2}
$$

$$
\begin{gathered}
v=r(N B) * A 1+r(N M) * \\
A 2+\cdots+r(P B) * A 7 \\
F i=y+v
\end{gathered}
$$

\section{Result and Discussion}

In this test, the fuzzy method used in the system was tested. Fuzzy used in the system is a fuzzy time series. The purpose of this test is to find out the output of fuzzy values from the system and fuzzy output from the expected output values. In this test, the procedure performed is to input through a sensor on the system. The results of the system output will be compared with the outputs calculated using manual calculations. Data retrieval is done 24 times which represents each condition in the rule that has been made in fuzzy rules:

\begin{tabular}{|c|c|c|c|}
\hline Hour to & Times & $\begin{array}{l}\text { Sensor } \\
\text { Result }\end{array}$ & Percentage \\
\hline 1 & 6:00 AM & 0 & $0 \%$ \\
\hline 2 & 7:00 AM & 760 & $76.00 \%$ \\
\hline 3 & 8:00 AM & 568 & $56.80 \%$ \\
\hline 4 & 9:00 AM & 540 & $54.00 \%$ \\
\hline 5 & 10:00 AM & 230 & $23.00 \%$ \\
\hline 6 & 11:00 AM & 205 & $20.50 \%$ \\
\hline 7 & 12:00 PM & 157 & $15.70 \%$ \\
\hline 8 & 1:00 PM & 168 & $16.80 \%$ \\
\hline 9 & 2:00 PM & 216 & $21.60 \%$ \\
\hline 10 & 3:00 PM & 278 & $27.80 \%$ \\
\hline 11 & 4:00 PM & 293 & $29.30 \%$ \\
\hline 12 & 5:00 PM & 302 & $30.20 \%$ \\
\hline 13 & 6:00 PM & 346 & $34.60 \%$ \\
\hline 14 & 7:00 PM & 390 & $39.00 \%$ \\
\hline 15 & 8:00 PM & 357 & $35.70 \%$ \\
\hline 16 & 9:00 PM & 398 & $39.80 \%$ \\
\hline 17 & 10:00 PM & 408 & $40.80 \%$ \\
\hline 18 & 11:00 PM & 420 & $42.00 \%$ \\
\hline 19 & 12:00 AM & 438 & $43.80 \%$ \\
\hline 20 & 1:00 AM & 460 & $46.00 \%$ \\
\hline 21 & 2:00 AM & 468 & $46.80 \%$ \\
\hline 22 & 3:00 AM & 540 & $54.00 \%$ \\
\hline 23 & 4:00 AM & 598 & $59.80 \%$ \\
\hline 24 & 5:00 AM & 670 & $67.00 \%$ \\
\hline
\end{tabular}

a. The process of acquiring soil moisture data Historical data used to predict using fuzzy time series is data every hour soil moisture data taken using soil moisture sensor technology as in Table 1.

Table 1. Data of actual soil moisture 
b. Defining universe of discourse $U$ until fuzzy set can be determined. After actual data was calculated, so minimal and maximal score of sample data was obtained $(X \min =157, X \max =845)$. Based on that score difference, the universe of discourse $U$ can be defined as $\mathrm{U}=[157,845]$.

c. Dividing universe of discourse $U$ with some data series $\mathrm{u} 1, \mathrm{u} 2, \ldots, \mathrm{un}$, and calculate the linguistic score. Firstly, the universe of discourse $U$ was divided into 3 intervals which have the same size, using the following way: Xmin + interval length. Interval length $=(\mathrm{Xmax}-\mathrm{Xmin}) / 3$ to describe variance of the selling number. Based on that definition, 3 fuzzy sets $\mathrm{A} 1, \mathrm{~A} 2, \mathrm{~A} 3$, in which $\mathrm{A} 1=$ (Negative Big), A2= (Zero), A3= (Positive Big). Inuniverse of discourse $U$ with the following scores: $\mathrm{A} 1=157, \mathrm{~A} 2=386, \mathrm{~A} 3=616$

d. Fuzzification of score from historical data. In the condition of membership functions (MBF) and fuzzy sets as illustrated in step 3, the actual score of selling number can be fuzzified with the norm: "if the actual score of selling number is $\mathrm{p}$ and score of $\mathrm{p}$ on the interval $\mathrm{Uj}$, so $\mathrm{p}$ can be translated as Aj". The fuzzifying final score of the selling number is based on the norms summarized in Table 1.

e. Calculating fuzzy score of selling number history data of product $A$, in each fuzzy set.

f. Choosing the base of model w which is very appropriate and calculating fuzzy operation.

g. Defuzzification of calculation in step 5, and then, calculate prediction result. After the calculation of fuzzy was done, we need to translate fuzzy output, next, the final prediction result was got. By using the Center of Gravity (COG) method and equality of (3) (4) (5) so it got final calculation result as shown in Table 2.

Table 2. Data of prediction result

\begin{tabular}{|c|c|c|c|c|}
\hline $\begin{array}{c}\text { Hour } \\
\text { To }\end{array}$ & Times & $\begin{array}{c}\text { Actual } \\
\text { Data }\end{array}$ & $\begin{array}{c}\text { Result } \\
\text { Prediction }\end{array}$ & Percentage \\
\hline 1 & $6: 00 \mathrm{AM}$ & 845 & 847 & $84.50 \%$ \\
\hline 2 & $7: 00 \mathrm{AM}$ & 760 & 762 & $76.00 \%$ \\
\hline 3 & $8: 00 \mathrm{AM}$ & 568 & 570 & $56.80 \%$ \\
\hline 4 & $9: 00 \mathrm{AM}$ & 540 & 542 & $54.00 \%$ \\
\hline 5 & $10: 00 \mathrm{AM}$ & 230 & 232 & $23.00 \%$ \\
\hline 6 & $11: 00 \mathrm{AM}$ & 205 & 207 & $20.50 \%$ \\
\hline 7 & $12: 00 \mathrm{PM}$ & 157 & 159 & $15.70 \%$ \\
\hline 8 & $1: 00 \mathrm{PM}$ & 168 & 170 & $16.80 \%$ \\
\hline 9 & $2: 00 \mathrm{PM}$ & 216 & 218 & $21.60 \%$ \\
\hline 10 & $3: 00 \mathrm{PM}$ & 278 & 280 & $27.80 \%$ \\
\hline 11 & $4: 00 \mathrm{PM}$ & 293 & 295 & $29.30 \%$ \\
\hline 12 & $5: 00 \mathrm{PM}$ & 302 & 304 & $30.20 \%$ \\
\hline 13 & $6: 00 \mathrm{PM}$ & 346 & 348 & $34.60 \%$ \\
\hline 14 & $7: 00 \mathrm{PM}$ & 390 & 392 & $39.00 \%$ \\
\hline 15 & $8: 00 \mathrm{PM}$ & 357 & 359 & $35.70 \%$ \\
\hline 16 & $9: 00 \mathrm{PM}$ & 398 & 400 & $39.80 \%$ \\
\hline & & & & \\
\hline
\end{tabular}

\begin{tabular}{|c|c|c|c|c|}
17 & $10: 00 \mathrm{PM}$ & 408 & 410 & $40.80 \%$ \\
\hline 18 & $11: 00 \mathrm{PM}$ & 420 & 422 & $42.00 \%$ \\
\hline 19 & $12: 00 \mathrm{AM}$ & 438 & 440 & $43.80 \%$ \\
\hline 20 & $1: 00 \mathrm{AM}$ & 460 & 462 & $46.00 \%$ \\
\hline 21 & $2: 00 \mathrm{AM}$ & 468 & 470 & $46.80 \%$ \\
\hline 22 & $3: 00 \mathrm{AM}$ & 540 & 542 & $54.00 \%$ \\
\hline 23 & $4: 00 \mathrm{AM}$ & 598 & 600 & $59.80 \%$ \\
\hline 24 & $5: 00 \mathrm{AM}$ & 670 & 672 & $67.00 \%$ \\
\hline
\end{tabular}

\subsection{Evaluation and validation of calculation result}

From evaluation and validation of error deviation toward fuzzy time series above, error deviation also has been tested by using the variance of number of universe of discourse starting from 3, 4, 5, 6 and 7. As well as data number starting from 12, 24, 36, 48, and 60 data. The result got is shown in Fig 3.

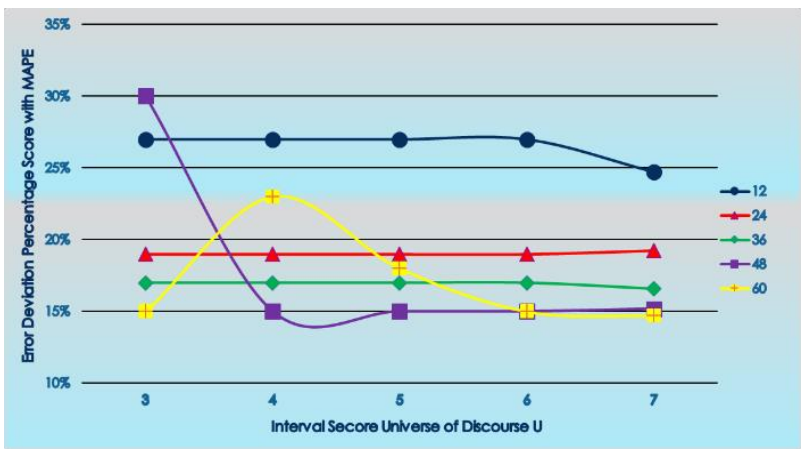

Fig 3. Error deviation score with MAPE

\section{Conclusion}

Prediction by applying a time series algorithm is done with variants of the interval score in the discourse universe and data number variances can be applied to predict soil moisture data. This can be proven by the results of testing using 24 data taken from the soil humidity sensor from 06.00 to 05.00 and the average error score obtained is $1.50 \%$ measured using the Mean Absolute Percentage Error (MAPE) method. Accuracy of prediction results is influenced by fluctuations in the amount of data, size (small and large) discourse universe interval scores, and minimum and maximum universe discourse scores.

\section{References}

1. M. Link, M. Drusch, K. Scipal, Assessment of Soil Moisture Information Content in Level-1 Data from Low-Frequency Active and Passive Microwave Sensors. IGARSS, 5386-7150 (2018)

2. N.R. Fernandez, P.D. Rosnay, C. Albergel, F. Aires, C. Prigent, P. Richaume, M. Drusch, Smos Neural Network Soil Moisture Data Assimilation, IGARSS, 5386-7150 (2018) 
3. E. Dai, A. Gasiewski, A. Venkitasubramony, M. Stachura, J. Elston, $L \neg$ Band Soil Moisture Mapping Using a Small Unmanned Aerial System. IGARSS, 4951-5090 (2017)

4. K.R.O. Putri, M. Syafrudin, Temperature and Soil Moisture in Post-Mining Revegetation Land in PT Adimitra Baratama Nusantara East Kalimantan, al AGRIFOR XVII, 1412-6885 , (2018).

5. B. Setyawan, M.H H. lchsan, E.G. Setyawan, Monitoring System for Soil Moisture, Air Humidity, and Temperature on Agricultural Land using the MQTT Protocol, Pengembangan Teknologi Informasị dan Ilmu Komputer 2, $7502-7508$ (2018)

6. Lutfiyana, N. Hudallah, A. Suryanto, Designing Soil Temperature Measuring Instruments, Jurnal Teknik Elektro 9 (2017)

7. B. Garg, M.M.S. Beg, A.Q. Ansari, Fuzzy Time Series Model to Forecast Rice Production, 1-8 (2013)

8. C. Mashuri, S. Suryono, J. E. Suseno, Prediction of Safety Stock Using Fuzzy Time Series (FTS) and Technology of Radio Frequency Identification (RFID) for Stock Control at Vendor Managed Inventory (VMI), in E3S Web of Conferences, (2018)

9. N.S. Bajestani, A. Zare, Application of Optimized Type 2 Fuzzy time series, 1-6 (2009)

10. Y. Lin, Y. Yang, Stock markets forecasting based on fuzzy time series model, 782 - 786 (2009)

11. Asniati, E.M. Hasiri, M.A. Suryawan, Application of Soil Moisture Sensor in Automatic Watering of Atmega 328 Microcontroller Plants, in Seminar Nasional APTIKOM (SEMNASTIKOM), (2017)

12. R. Oktavianus, Isnawaty, N.F. Muchlis, Design and Implementation of Soil Moisture Monitoring System in Android Based," ANDROID, 3 (2), 59-268 (2017) 